\title{
Vascular Patterns of the Human Testis with Special Reference to Its Senile Changes
}

\author{
Nobuaki Sasano \\ Department of Pathology (Prof. N. Sasano) \\ and \\ Sadatoshi Ichijo \\ Department of Urology (Prof. S. Shishito), \\ Tohoku University School of Medicine, Sendai
}

\begin{abstract}
Senile changes of the human testis from 121 autopsy cases were histologically examined in 6 topographic parts which were divided by the microangiography, and the findings were discussed in relation to blood supply.

Focal depletion of spermiogenesis with thickening of the basement membrane of seminiferous tubules appeared in the fourth and fifth decades and pigmentation of the interstitial cells later. The senile changes were not uniform in severity throughout the testis and were induced in a distribution pattern with a close relation to blood supply.

Main arteries of the testis descended along the medial surface to the lower pole and turned up along the lateral surface to the upper pole. On the upward way the main arteries extended branches toward the mediastinum. Therefore, the upper pole and the posterior part adjacent to the mediastinum belonged to the distal area in the arterial supply and showed advanced senile changes in general. Hernia-like protrusions, however, were prevalent in the lower and anterior parts proximal to the arterial trunk.
\end{abstract}

As for histological manifestations of senile changes in the testis, it has been generally accepted that the seminiferous tubules are frequently dilated in association with depletion of spermiogenesis, and hernia-like protrusion and thickening of the basement membrane leading to fibrous atresia of the tubules. Furthermore, Leydig cells are pigmented and arterioles show sclerotic changes. These lesions usually differ in severity from part to part of the testis, but are uniform within circumscribed areas. This seems to be related with blood supply. The present paper deals with microangiographic patterns of blood supply in the testis and with an interpretation on the histological distribution of senile changes.

\section{Materials and Methods}

Materials used were the testes obtained from 121 autopsy cases of Japanese ranging from 14 to 73 years of age. The method of microangiographic examination applied to

Received for publication, July 9, 1969. 
39 testes were as follows: After preliminary washout of the vascular system with saline solution containing heparin in $1000 \mu / \mathrm{l}$ for an hour, 3 to $7 \mathrm{ml}$ of $60 \%$ Micropaque suspension were injected into the testicular artery or vein under a constant pressure of $100 \mathrm{~mm} \mathrm{Hg}$. The materials were fixed in formalin, and the whole testis and its serial slices $3 \mathrm{~mm}$ in thickness were radiographed with a Softex of either EBM or CMR using a Fuji fine grain film for Softex.

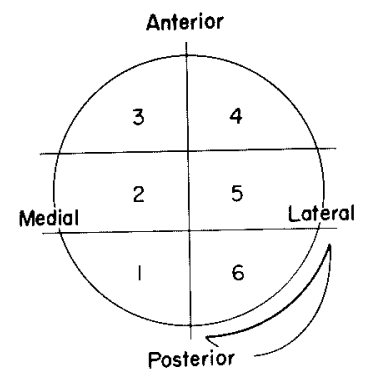

Horizontal sectlon

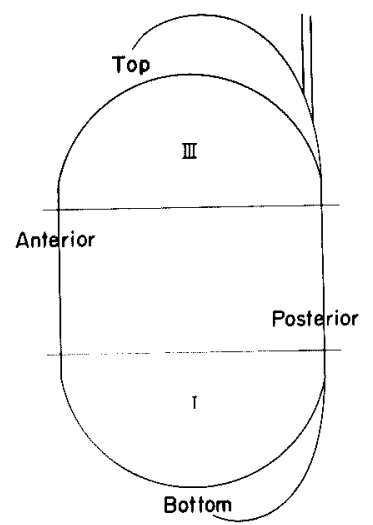

Sagiftal section

Fig. 1. Topographic areas in horizontal and sagittal sections.

Specimens for histological examination were obtained from the remaining 82 testes by horizontal and sagittal sections to find topographic orientation. Horizontal slices were divided into six parts; medial and lateral areas in anterior, middle and posterior parts. Sagittal slices were divided into three parts; upper, middle and lower (Fig. 1). Each part was compared with others in every case and also with the same part in every decade.

The specimens were fixed mostly in $10 \%$ formalin and partly in Zenker-formol or Bouin's solution. Paraffin sections were made and stained with hematoxylin and eosin, MassonGoldner's trichrome stain and PAS.

\section{Results}

\section{1) Vascular patterns}

In the 36 cases examined, arterial blood supply from 1,2,3 and more main arteries was observed in 5 cases $(14 \%), 20(56 \%), 8(22 \%)$ and $3(8 \%)$, respectively, although there were several anatomical variations. These arteries penetrated the capsula albuginea adjacent to the hilus, and descended along the medial surface of the testis. The main arteries turned up along the lateral surface to the upper pole, and spread several branches along the seminiferous tubules toward the mediastinum. In other words, the lower and anterior parts were proximal to the arterial trunk,

Figs. 2-4: Arteriograms of the right testes by the side-view from left to right. One or more main arteries nourish the testis. The upper pole (on the left in Figs. 2-4) is situated at the periphery of arterial supply. 

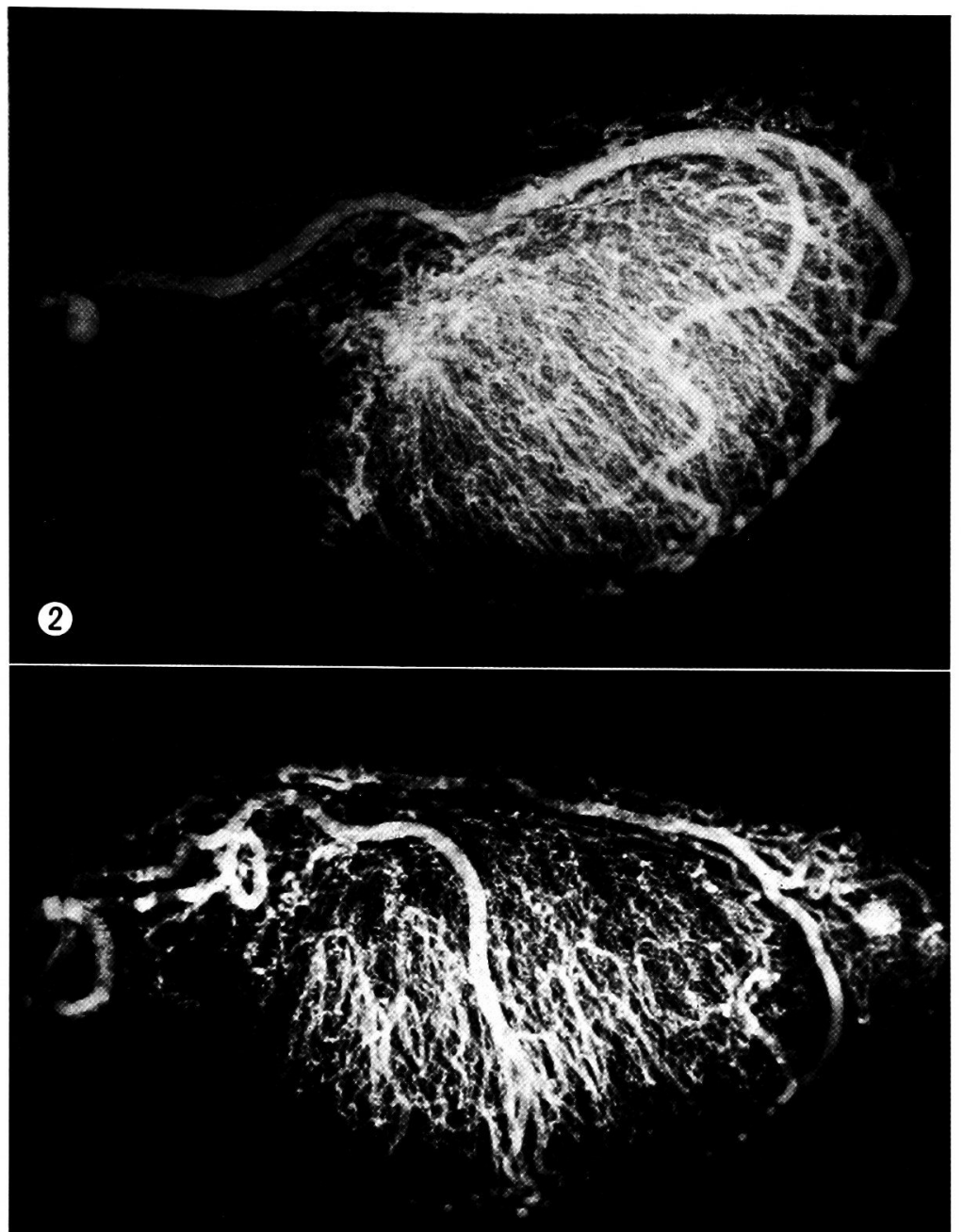

(3)

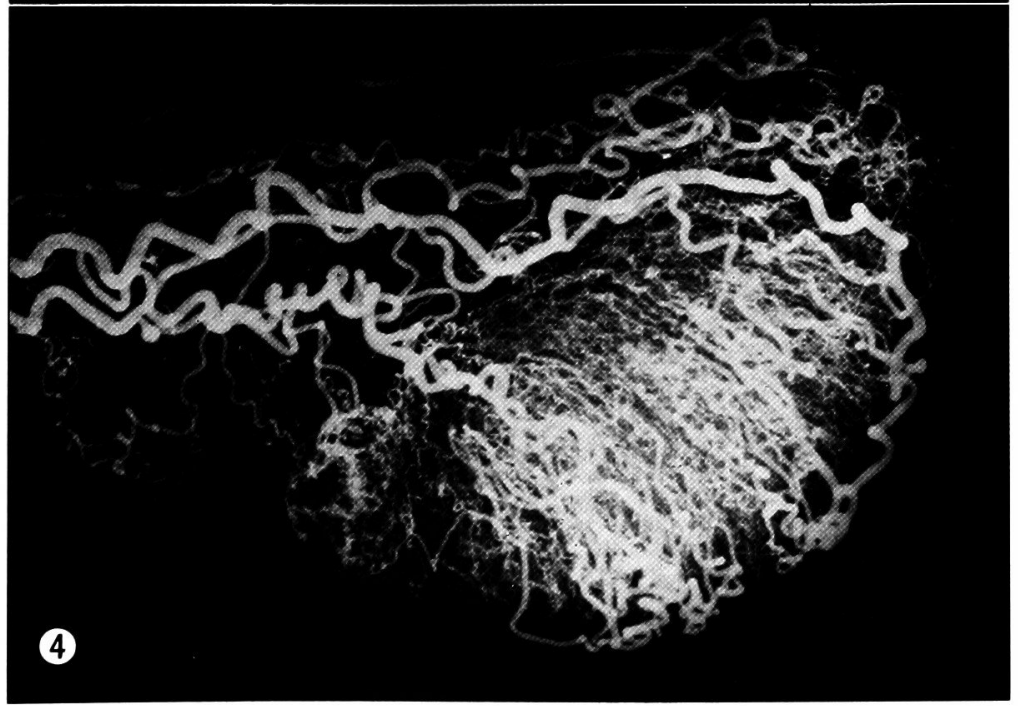




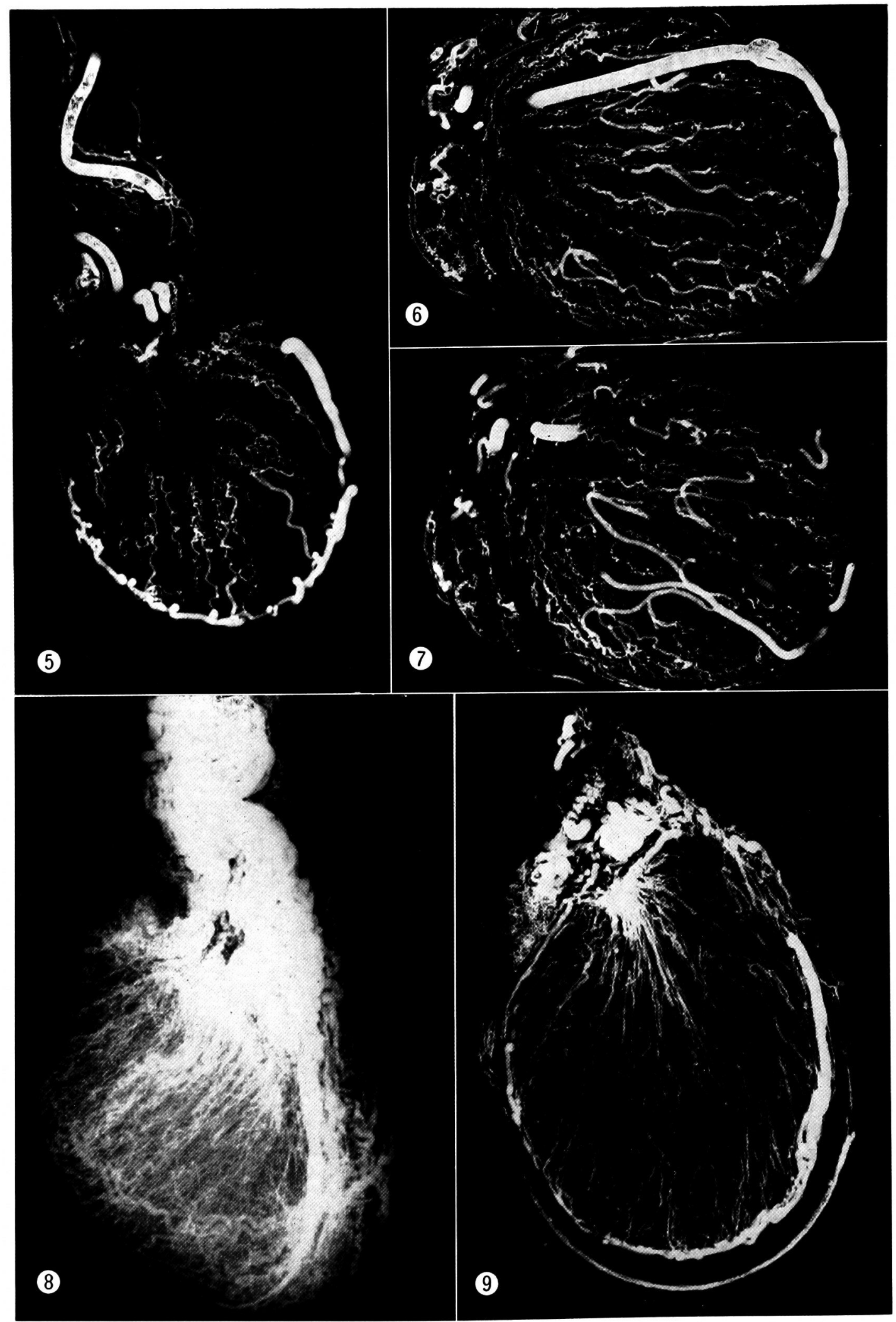


and the upper part and mediastinum were situated at the periphery of blood supply (Figs. 2-7).

Venous patterns were quite different from the arterial ones. The anterior part of the testis was drained by fine veins, which originated around the seminiferous tubules and flowed centrifugally into the main veins. The main veins ran parallel with main arteries. On the other hand, fine veins from the posterior half of the testis flowed into the venous plexus of the mediastinum. At the hilus the main veins joined the venous plexus to make the pampiniform plexus (Figs. 8 and 9).

\section{2) Histology}

For the evaluation of histological changes, the degree of spermiogenesis, incidence of hernia-like protrusion, thickness of the basement membrane, and quantity of brown pigment and Reinke's crystalloid in Leydig cells were described on every testicular part in each decade.

Horizontal sections. The degree of spermiogenesis was indicated by a percentage of the total number of tubules with spermatids and the results were shown in Fig. 10. The mean value was around $90 \%$ in the third and fourth decades, but dropped to $50 \%$ in the fifth decade. It decreased further in the eighth decade and finally reached to around $10 \%$ in the ninth decade.

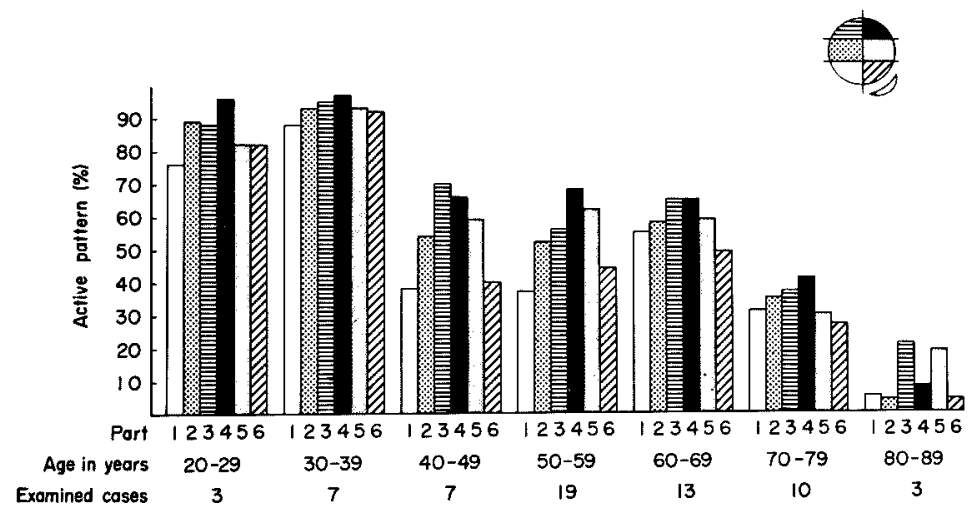

Fig. 10. The incidence of tubules with spermatids by age in horizontal sections.

Figs. 5-7: Arteriograms of horizontal slices of the testis. The main artery runs along the medial to lateral surface (on the right and left in Fig. 5) and it occasionally penetrates parenchyma to reach the anterior surface (right side in Fig. 6). The main artery at the surface extends branches toward the mediastinum (left part in Fig. 7), but in exceptional cases it turns back to the parenchyma. The posterior part is situated at the periphery of arterial supply.

Figs. 8 and 9: Venograms of the whole (Fig. 8) and a horizontal slice (Fig. 9) of the testis, into which Micropaque suspension was injected through the spermatic vein. The anterior half of the testis drains into the main veins of the surface and the posterior half drains into the venous plexus of the mediastinum. 
Among 6 parts in the horizontal section, the anterior part proximal to the arterial trunk had the highest value in all decades, while the posterior part at the periphery of arterial supply had the lowest one.

The incidence of hernia-like protrusions was shown in Fig. 11. The figures showed a general tendency to increase with age up to the sixth decade and to decrease thereafter. Through all decades the protrusions generally prevailed in the anterior parts (Nos. 3 and 4), which were proximal to the arterial trunk.

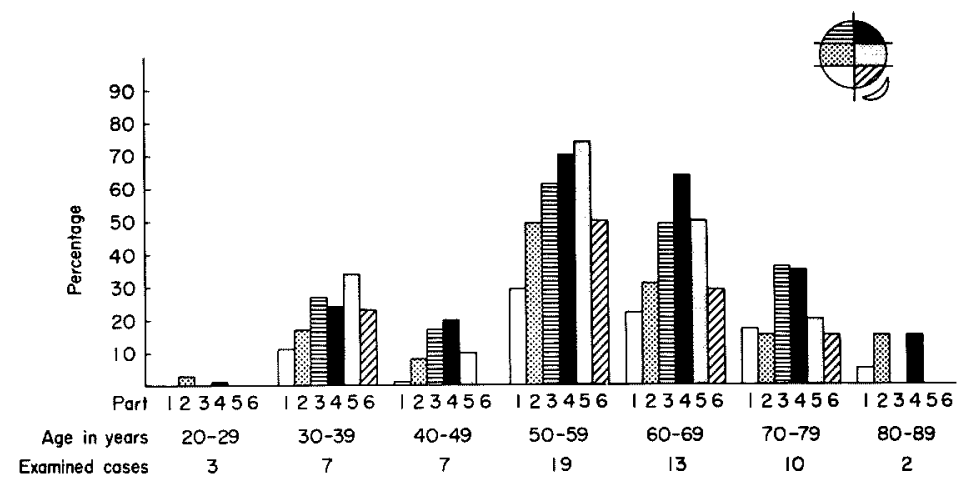

Fig. 11. The incidence of hernia-like protrusions by age in horizontal sections.

Thickness of the basement membrane was not always easy to compare, but in certain cases the thickened basement membrane was prevalent in the posterior part, but not in the anterior part (Figs. 12 and 13, and Table 1). Thickening of the basement membrane of seminiferous tubules according to aging was generally more evident in the periphery of arterial supply than that in the proximal parts, and the incidence of such cases increased up to the sixth decade. After the age of sixty the thickened basement membrane with uniform lesions was observed more widely also in the proximal parts, while cases with difference in grades of fibrosis between distal and proximal parts tended to decrease.

Leydig cells abundant in lipofuscin pigment were generally prominent in the posterior part and those with Reinke's crystalloids prevailed in the anterior part (Figs. 14-17). There was no case of reversed distribution. Table 1 indicated actual numbers and percentages of cases with pigmented Leydig cells prevalent in the posterior part and those with crystalloid containing cells prevalent

Figs. 12 and 13: The basement membrane of tubules from a man aged 59 years. Compared with tubules in the anterior part (Fig. 12), the tubules in the posterior part (Fig. 13) have a thick basement membrane and sparse cell components.

Figs. 14 and 15: Pigmentation in Leydig colls is more marked in the posterior part (Fig. 15) than that in the anterior part (Fig. 14).

Figs. 16 and 17: Reinke's crystalloids in Leydig cells from a 58-year-old man. The crystalloids are observed more frequently in the anterior part (Fig. 16) than in the posterior part (Fig. 17). 


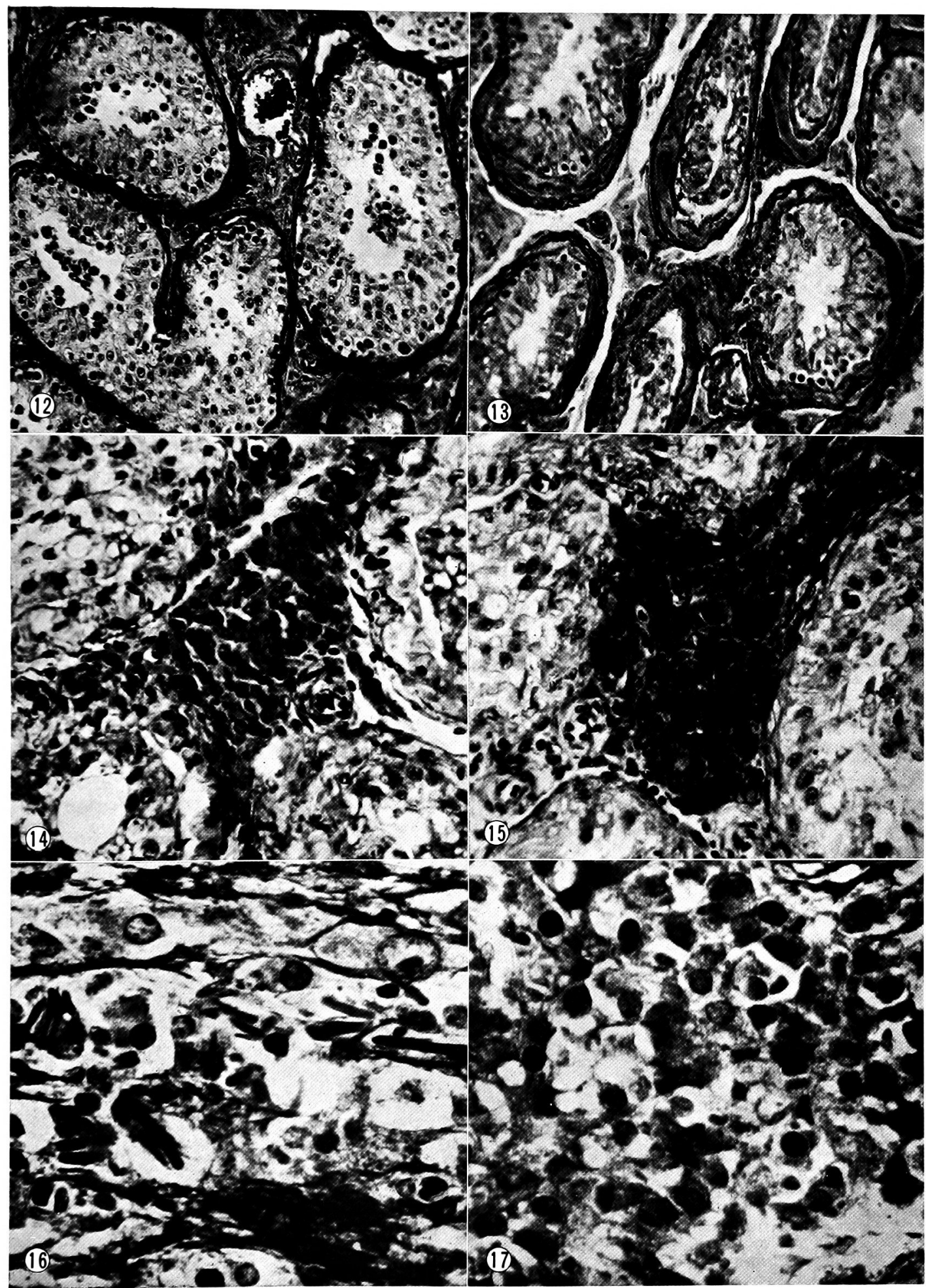


TABLE 1. Cases with differences between anterior and posterior parts

\begin{tabular}{|c|c|c|c|c|c|c|c|c|}
\hline & Age & $20-29$ & $30-39$ & $40-49$ & $50-59$ & $60-69$ & $70-79$ & $80-89$ \\
\hline \multicolumn{2}{|c|}{ Number of cases } & 3 & 7 & 7 & 19 & 13 & 10 & 2 \\
\hline \multicolumn{2}{|c|}{$\begin{array}{l}\text { Thickness of the } \\
\text { basement membrane }\end{array}$} & $1(33 \%)$ & $3(43 \%)$ & $5(71 \%)$ & $18(95 \%)$ & $8(629)$ & $6(60 \%)$ & $1(50 \%)$ \\
\hline \multirow{3}{*}{ 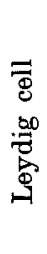 } & $\begin{array}{l}\text { Frequency of } \\
\text { Reinke's } \\
\text { crystalloids }\end{array}$ & $0(0 \%)$ & $0(0 \%)$ & $3(43 \%)$ & $7(37 \%)$ & $6(46 \%)$ & $3(30 \%)$ & $0\left(\begin{array}{ll}0 & \%\end{array}\right)$ \\
\hline & $\begin{array}{l}\text { Degree of } \\
\text { pigmentation }\end{array}$ & $0(0 \%)$ & $1(14 \%)$ & $2(29 \%)$ & $7(37 \%)$ & $5(38 \%)$ & $5(509)$ & $2(100 \%)$ \\
\hline & Either of above & $0(0 \%)$ & $1(14 \%)$ & $5(71 \%)$ & $14(74 \%)$ & $8(61 \%)$ & $6(60 \%)$ & $2(10096)$ \\
\hline
\end{tabular}

in the anterior part. The cases with difference in either pigmentation or crystalloid between anterior and posterior parts generally increased with age up to the sixth decade. The incidence exceeded $60 \%$ in every decade over 40 years of age.

Sagittal sections. The incidence of tubules with spermiogenesis decreased with age and suddenly fell in the fifth decade. The mean percentage of the tubules with spermatids was $67 \%$ in the lower, $57 \%$ in the middle and $50 \%$ in the upper parts. Spermiogenesis was depressed more evidently in the upper part which was situated at the periphery of arterial supply than in others, and this tendency was distinct after the age of forty (Fig. 18).

Hernia-like protrusions were seen in $2.3 \%$ of the tubules. As shown in Fig. 19 , the percentage increased with aging up to the seventh decade and decreased thereafter. In most decades the protrusion was prevalent in the lower part proximal to the arterial trunk, and the result agreed to that of the horizontal section.

Thickening of the basement membrane and degeneration of Leydig cells were found more advanced in the upper part (Table 2).
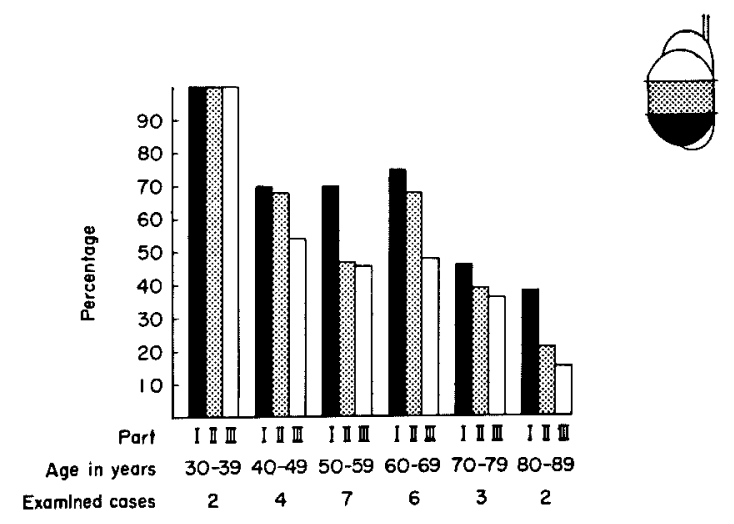

Examined cose

Fig. 18. The incidence of tubules with spermiogenesis by age in sagittal sections. 


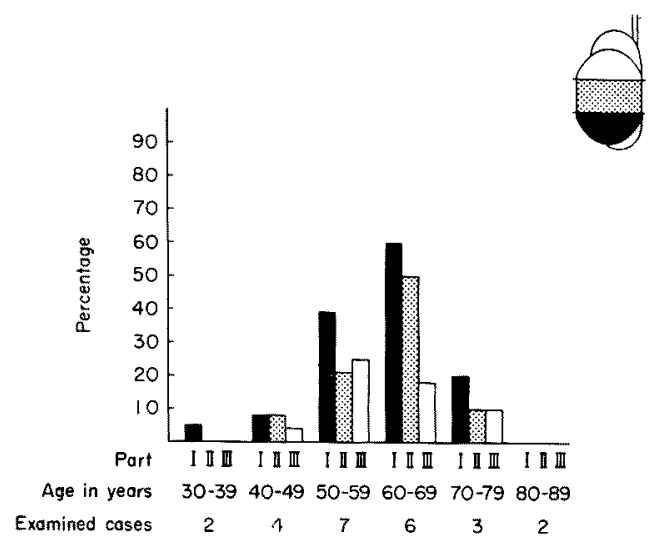

Fig. 19. The incidence of hernia-like protrusions by age in sagittal sections.

TABLE 2. Cases with differences between upper and lower poles

\begin{tabular}{c|c|c|c|c|c|c}
\hline Age & $30-39$ & $40-49$ & $50-59$ & $60-69$ & $70-79$ & $80-89$ \\
\hline $\begin{array}{c}\text { Number of cases } \\
\begin{array}{c}\text { Thickness of the } \\
\text { basement } \\
\text { membrane }\end{array}\end{array}$ & 2 & 4 & 7 & 6 & 3 & 2 \\
\hline $\begin{array}{c}\text { Pigmentation of } \\
\text { the Leydig cell }\end{array}$ & $0(0 \%)$ & $1(20 \%)$ & $2(29 \%)$ & $2(33 \%)$ & $1(33 \%)$ & $1(50 \%)$ \\
\hline
\end{tabular}

In general, senile changes were more pronounced in the distal area of arterial supply. An exceptional change was hernia-like protrusion, which increased with age up to the sixth and seventh decades and decreased thereafter and was found prevalently in the proximal area of arterial supply (Figs. 20-25). This finding was contrary to that of other changes.

\section{Discussion}

Anatomy of the testicular artery was studied elaborately by Harrison and Barclay $^{1}$ and most of the present observations agreed well with their description. However, in the present study no case was found in which arteries branched on the lateral surface, although it had been not rarely observed by Harrison and Barclay. ${ }^{1}$

They described two patterns of venous supply, one of which had one or two large anastomotic venous channels running approximately through the middle of the testis. This could not be confirmed by the present observation on three cases of venogram, but histologically observed in only one case. Consequently, the venous patterns described by Harrison and Barclay seem to be comparatively rare in Japanese. 

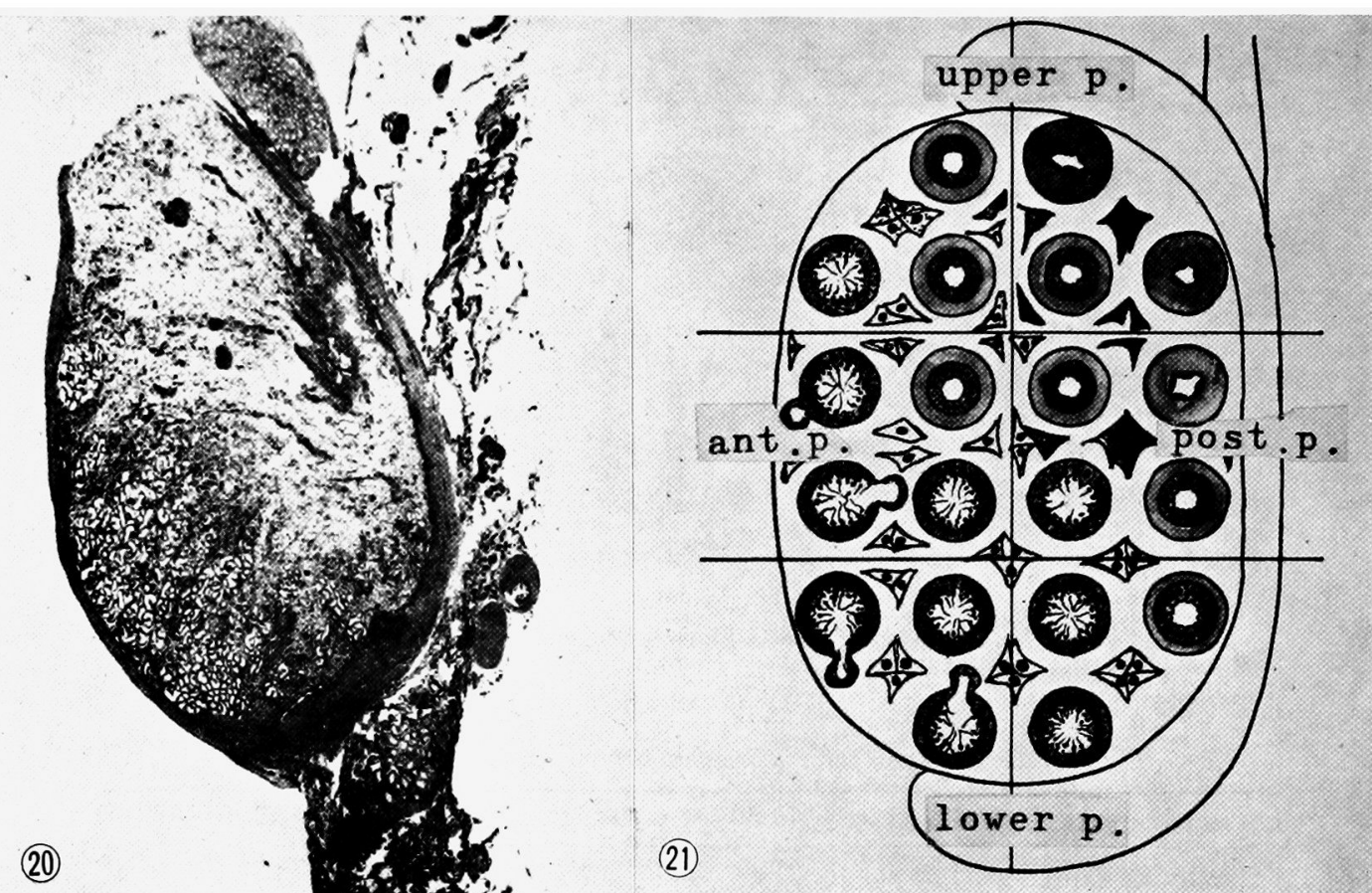

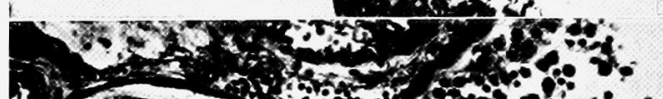
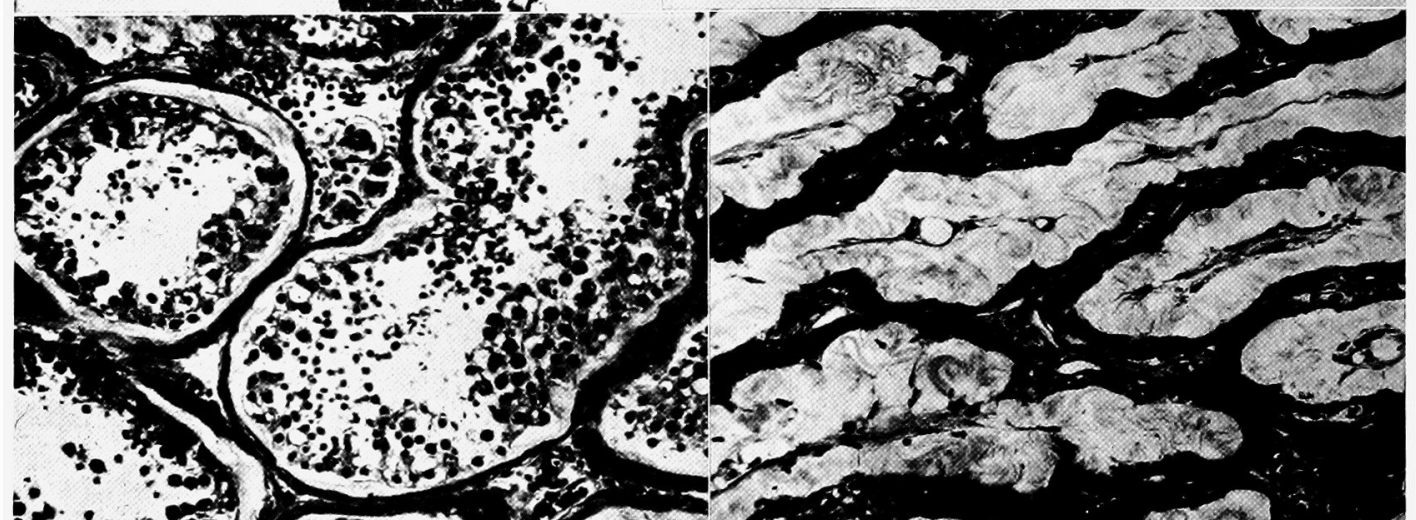

3.

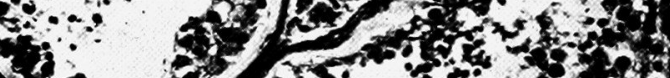

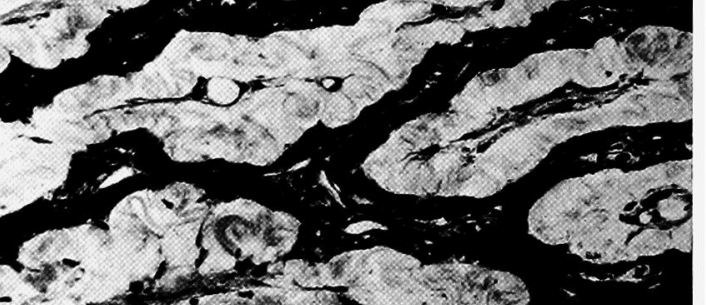

(22)
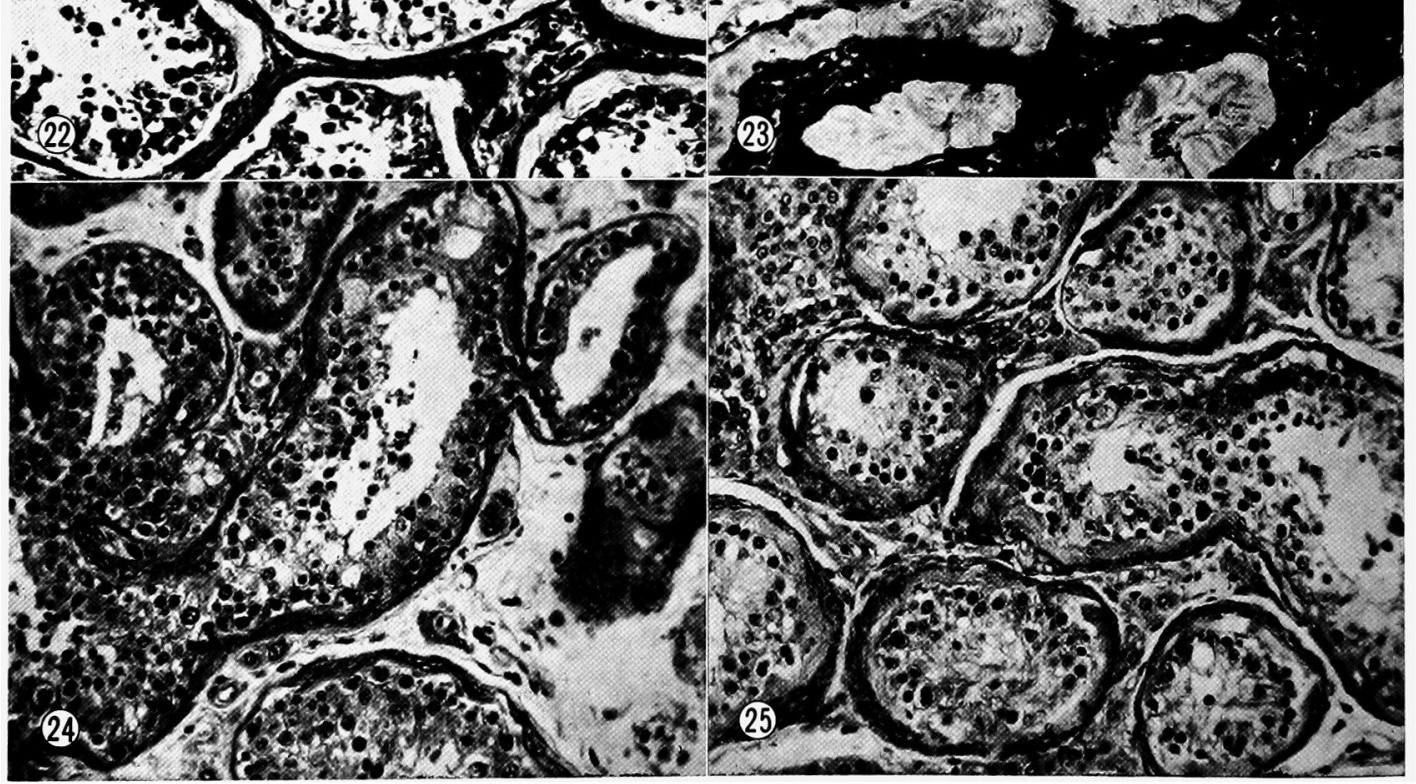
Although there are certain racial differences in the vascular pattern of the testis, the mediastinum and upper pole are unexceptionally distal to the artarial trunk. This fact may offer an explanation for intratesticular distribution of senile changes. The present authors have experienced cases with torsion of the spermatic cord and testicular infarction, which caused very severe changes at the top and mediastinum of the testis. Therefore, it is importunt to clurify the difference in garde of severity of the lesions between the proximal and dist.ul parts of arterial supply, but there has been no report available in the litrrature.

From this standpoint the present authors examined the degree of spermiogenesis, thickness of the basement membrane, hernia-like protrusion, and pigmentation and Reinke's crystalloids in Leydig cells in various parts of the testis in relution to the blood supply. These changes would not be specific to the aging process but are exceedingly prominent in the senile testis. Our results suggest that these changes may be induced by a disturbance of blood supply in old ages and consequently are more advanced in the distal part of arterial supply. The hernix-like protrusion was regarded as an atrophic senile change of the tastis and consilered to be a budding regeneration of the seminiferous tubules. ${ }^{2}$ The present authors, however, revealed that the protrusion was associsted in the tubules with an active spermiogenesis and prominent in the proximal part of arterial supply. This finding was scanty in the senile testis, while it was seen even in the testis of an adolescent. Accordingly the hernia-like protrusion is more likely a step in development of the seminiferous tubules. It has been known that the seminiferous tubules in the senile testis often have branches or bridges between tubules. The protrusion could be considered to be a bud of the branch or bridge.

It has been known that the lipid content of Leydig cells increases up to the second to third decade and decreases thereafter. ${ }^{3}$ Pigmentation of Leydig cells is accelerated with advancing age, but Reinke's crystalloids diminish on the contrary. 4,5 According to our study, the crystalloids were found prominently in the proximal part of the testis, and the pigmentation prevailed in the periphery of arterial pattern in the senile testis. Asile from tubular changes, these findings on interstitial cells also suggest the presence of a close correlution between histological changes and blood supply.

It has been known that senile changes of the testis are characterized by marked arteriolosclerosis associated with severe hyalirizction and frequently with stenosis of the lumen. Therefore, lesions due to circulatory cisturkances

Figs. 20 and 21: Distribution of the lesions of sezile chnnges. The lesions are pronineat in the upper pole and the posterior part located at the periphery of urterial supply.

Figs. 22 and 23: Differezces in severity of fibrous atresia of the trbule in a mon aged 74 years. Spermioge-aesis is relatively well preserved (Fig. 22 at the lower pole while it is profoundly diminished at the upper pole resulting in complete fibrous atresia of the tubule extensively (Fig. 23).

Figs. 24 and 25: Hernia-like protrusions of the tubule o'sserved in a cuse agel 58 yeurs. The protrusions are seen more prominently in the anterior purt (Fig. 21) than in the posterior part (Fig. 25). 
are most likely induced in the distal area.

In conclusion, most of senile changes of the testis have a close correlation with blood supply, and these changes are exaggerated in the parts near the upper pole and the mediastinum, which are situated at the distal area of arterial supply. Hernia-like protrusions, which are prevalent in the lower and anterior parts proximal to the arterial trunk, are considered to be a bud to develop into a branch or an anastomotic bridge of the seminiferous tubules.

\section{References}

1) Harrison, R.G. \& Barclay, A.E. The distribution of the testicular artery to the human testis. Brit. J. Urol., 1948, 20, 57-66.

2) Hatakeyama, S., Sengoku, K. \& Takayama, S. On the hernia-like protrusions suggestive of regeneration of the human seminiferous tubule. Bull. Tokyo Med. Dent. Univ., 1962, 9, 471-481.

3) Lynch, K.M., Jr. \& Scott, W.W. The lipid content of the Leydig cell and Sertoli cell in the human testis as related to age, benign prostatic hyperplasia, and prostatic cancer. J. Urol., 1950, 64, 767-776.

4) Sniffen, R.C. The testis. I. The normal testis. Arch. Path., 1950, 50, 259-284.

5) Sn ffen, R.C., Howard, R.P. \& Simmons, F.A. The testis. II. Abnormalities of spermatogenesis; atresia of the excretory ducts. Arch. Path., 1950, 50, 285-295. 